\title{
Revelação e Literatura: aproximações teológicas segundo Adolphe Gesché
}

\author{
Revelation and Literature: \\ approaches Theological according to Adolphe Gesché
}

\author{
Alexandre Patucci de Lima
}

\section{Resumo}

A "Revelação" tem sido um tema central da Teologia contemporânea. Também a "Literatura" passou a ter lugar cada vez mais vasto no âmbito teológico. Na sua abordagem sobre Teologia e Literatura, Adolphe Gesché assinala analogias entre o fazer literário e a categoria teológica de "revelação". Tal correlação permite pensar de maneira mais dinâmica o próprio sentido da Revelação, auxiliando no desenvolvimento de uma teologia mais ligada à vida. O discurso teológico comporta uma antropologia, pois não é somente um discurso sobre Deus, mas um discurso que ao falar de Deus fala ao homem. Esta antropologia teológica é associada por Gesché a uma antropologia literária. A pesquisa literária pode auxiliar o teólogo a compreender aspectos de seu discurso. A literatura possui um poder de "revelação" de mundo, que auxilia na compreensão e desenvolvimento de uma teologia capaz de ser reveladora, lugar onde o ser humano pode buscar conhecer-se.

Palavras-chave: Revelação. Literatura. Teologia. Adolphe Gesché.

\section{Abstract}

The "Revelation" has been a central theme of contemporary theology. Also the "Literature" has to take place increasingly large in the theological context. In his approach to theology and literature, Adolphe Gesché points 
analogies between the 'doing literary' and the theological category of "revelation". Such correlation allows us to think more dynamically the very meaning of Revelation, assisting in the development of a more connected to life Theology. The theological discourse holds an anthropology as it is not only a discourse on God, but a speech that speaking about God speaks to man. This theological anthropology is associated by Gesché to a literary anthropology. The literary research can help the theologian to understand aspects of his speech. The literature has a power of "revelation" of the world, which helps in the understanding and development of a theology able to be revealing, place where the human being can seek to know himself.

Keywords: Revelation. Literature. Theology. Adolphe Gesché.

\section{Introdução}

Um dos temais centrais da Teologia contemporânea tem sido a questão da Revelação. Desde o século XIX, e em todo processo da renovação teológica que conduziu ao Concílio Vaticano II, este tema tem sido debatido e desenvolvido, tanto que o próprio Concílio dedicou um documento a esta questão, a Constituição "Dogmática Dei Verbum”. Sem adentrar nos meandros das questões relativas às discussões em torno da natureza da Revelação, convém destacar apenas uma mudança significativa no modo de se abordar esta questão: até então se considerava a Revelação mais na perspectiva do conhecimento, e dessa forma havia uma tendência a abordá-la quase como se fosse uma "lista de verdades caída do céu"; 1 com o Vaticano II, mais do que uma "lista de verdades", a Revelação passa a ser abordada mais como "Autocomunicação de Deus", ${ }^{2}$ fato que propicia novos horizontes para se aprofundar e se pensar o significado da Revelação.

Também a Literatura passou a ter um lugar cada vez mais amplo na abordagem teológica, na medida em que a renovação teológica buscou ir além de

\footnotetext{
1 “A negação por parte do deísmo da existência de uma religião sobrenatural e revelada vai fazer com que os apologetas insistam na necessidade da revelação como fonte à parte e exclusiva de verdades que estão fora do alcance da razão. A escolástica barroca acaba identificando estas verdades com a revelação. O Vaticano I herda a identificação" BOTTIGHEIMER, Christoph. Manual de Teologia Fundamental: A racionalidade da questão de Deus e da Revelação. Petrópolis: Vozes, 2014, p. 44.

${ }^{2}$ Cf. Constituição Dogmática Dei Verbum, 6: "Pela revelação divina quis Deus manifestar-se e comunicar-se a si mesmo".
} 
uma Teologia centrada na especulação escolástica que já não era capaz de "responder" à situação moderna e contemporânea em face aos avanços da ciência, da pesquisa bíblica, e do contexto social, político e antropológico do homem atual. Até então se percebia prevalecer uma separação entre Teologia e vida:

Entre as causas da atual crise do cristianismo, podemos mencionar certo divórcio entre teologia e experiência de fé da comunidade cristã, divórcio cujas origens longínquas remontam à instauração da teologia científica, construída como técnica especializada, culminando na dialética escolástica. $\mathrm{O}$ uso do latim como língua técnica transformou desde longa data a teologia num 'domínio' reservado aos iniciados. Neste caso, a teologia se alimenta de si própria, repete-se indefinidamente, em vez de nutrir-se da vida. O teólogo considerará nula, se não herética, a experiência vivida do leigo que não entre nos seus quadros; e o leigo, ignorando a teologia, não poderá compreender corretamente a própria experiência. ${ }^{3}$

Buscando ir além de si mesma, indo de encontro às alegrias e angústias dos homens e mulheres de seu tempo, os teólogos passam a abarcar, no fazer teológico, a experiência concreta da vida e do contexto do homem contemporâneo, e com isso aproximam-se também da Literatura por ser lugar onde é possível conhecer o ser humano em suas expressões e possibilidades existenciais, já que nela se "revelam valores vividos pelos homens; ela mostra uma compreensão do homem, ela fala sempre do homem, apresenta-o, critica-o, mostra o homem vivendo". ${ }^{4}$ Inúmeros autores irão articular a arte e a Literatura com a Teologia por diversos ângulos e aspectos buscando através da arte e da literatura não só comunicar a mensagem cristã (Literatura cristã), mas buscar fonte para ao crescimento na compreensão do ser humano (Literatura em geral), e buscar compreender a própria natureza da linguagem teológica que tem sua fonte na Escritura, marcada por diversos gêneros literários (poema, poesia, narrações, crônicas, etc..). Percebeu-se que a compreensão da linguagem literária poderia auxiliar na compreensão da linguagem bíblica, religiosa e consequentemente teológica.

Neste trabalho, prescindindo-se de adentrar nas discussões sobre a natu-

\footnotetext{
${ }^{3}$ ROUSSEAU, Hervé. “A Literatura: Qual é seu poder teológico?”. Concilium 115 (1976/5), p. 7. ${ }^{4}$ MANZATTO, Antonio. Teologia e Literatura: reflexão teológica a partir da antropologia contida nos romances de Jorge Amado. São Paulo: Edições Loyola, 1994, p. 7.
} 
reza da Revelação e sobre as questões técnicas de Literatura, procura-se destacar uma dentre as abordagens possíveis entre Teologia e Literatura, a partir da obra de Adolphe Gesché, não focando todo seu pensamento, mas destacando apenas alguns aspectos nos quais refletiu sobre a relação entre Revelação e Literatura, em vista de contribuir na crescente consciência da dinamicidade da Revelação.

\section{Adolphe Gesché: experiência literária e vocação teológica}

O pensamento e a teologia de Adolphe Gesché são notoriamente marcados pela presença da Literatura. Pode-se dizer que Gesché possui uma maneira "sui generis" de fazer Teologia, e isso se pode constatar também na simples observação das referências de suas citações, a maior parte, de romancistas, ensaístas, poetas, filósofos (envolvidos com questões de literatura), ${ }^{5}$ etc. Para Gesché, eles são "considerados parceiros importantes do pensamento teológico", ${ }^{6}$ não somente porque a Literatura pode ilustrar artisticamente e exemplificar uma "verdade teológica", mas porque ela mesma pode se constituir em fonte de "revelação" daquilo que é humano (e do que é divino - a palavra de Deus não deixa de ser Literatura); e tudo aquilo que é humano, a partir da Encarnação, não pode deixar de ter lugar na Teologia. Esta forma de considerar a Literatura (e Teologia) advém da própria experiência do autor.

Adolphe Gesché nasceu em 1928 em Bruxelas, na Bélgica. Viveu boa parte de sua adolescência e juventude sob os horrores e consequências da guerra, e nesse contexto descobriu os livros. ${ }^{7}$ Ele mesmo diz dessa época: "Eu não vivi a não ser de símbolos (haja vista minha juventude, onde todo resto estava excluído por causa da guerra). Que chance!"8 Gesché experimentou diante desta situação a possibilidade de descortinar "mundos" através da leitura, e não obstante a guerra que lhe impossibilitava muitas coisas, pôde perceber o quanto a leitura, longe de lhe afastar da realidade, a ela o conduziu. Por isso, mais tarde, numa de suas obras, escreveu: "Não é a story, a historia inventada (conto de fadas,

\footnotetext{
${ }^{5}$ Citações estas cada vez mais frequentes em suas últimas obras, ao contrário das primeiras em que tais citações eram raras. Cf. LOBET, Benoit. "La littérature". In : BOURGINE, Benoit et al. La Margelle du puits. Adolphe Gesché, une introduction. Paris: Cerf, 2013, p. 247.

${ }^{6}$ Idem, p. 247.

${ }^{7}$ Nos últimos anos de vida, organizou um livro dedicado às "palavras e aos livros": GESCHÉ, Adolphe. Les mots et lês livres. Paris: Cerf, 2004.

${ }^{8}$ GOSSELIN, Jean-François. "La Vie". In: BOURGINE, Benoit et al. La Margelle du puits. Adolphe Gesché, une introduction. Paris: Cerf, 2013, p. 39.
} 
etc.) que permite, e só ela permite, à criança entrar, um dia na historia real sem se arrebentar?" Gesché encontrou nos livros o "tesouro da terra dos homens". ${ }^{10}$

O gosto pela Literatura, segundo o próprio Gesché, veio principalmente pela influência da mãe, enquanto o pai, médico, mesmo sendo católico praticante, era marcado por um catolicismo liberal, de cunho racionalista e crítico, de modo que a biblioteca da casa de seus pais não era formada apenas por livros "piedosos e devocionais". Assim, Gesché criou-se lendo clássicos da literatura cristã, como também da literatura em geral, inclusive, segundo ele, de autores "marcados no Index". Foi neste lugar que certamente "fez a experiência desta humanidade que nos une uns com os outros, no que temos de mais profundo e mais caro", já que a Literatura tem esse potencial de revelação do "humano". Também aí nesse lugar de "transgressão literária" se anuncia uma liberdade de espírito que o caracterizará mais tarde. ${ }^{11}$

Não obstante esta abertura de espírito de sua família, fez no seio da mesma a experiência concreta da vivência familiar da fé, já que sua família era católica praticante. Se com a família fez concretamente a experiência cristã, esta também se realizou a partir das leituras a que tinha acesso na biblioteca de sua casa, e a partir de tais experiências se pode dizer que "o dogma estava inscrito em seu coração, com palavras doravante irrefutáveis". De fato, para Gesché, "a experiência de Deus foi indissociável do encontro com as palavras e os livros. Para ele toda biblioteca é um verdadeiro santuário, lugar de epifania e revelação". ${ }^{12}$

Terminados os estudos fundamentais, Gesché ingressa na faculdade de Filosofia e Letras, onde conclui o curso com uma especialização em Filologia Clássica. Foi durante o tempo de faculdade que se decide pela vocação sacerdotal, seguindo também o caminho da Teologia.

\section{Projeto Teológico: Deus para pensar}

Gesché conclui seu doutorado em Teologia estudando a Cristologia patrística (influência de seus estudos em Filologia), e quando passa a lecionar Teologia, primeiro no Seminário de Malines (1962-1969), e de-

\footnotetext{
${ }^{9}$ GESCHÉ, Adolphe. O sentido. São Paulo: Paulinas, 2003, p. 145.

${ }^{10}$ GESCHÉ, Adolphe. Les mots et lês livres, p. 23.

${ }^{11}$ Cf. GOSSELIN, Jean-François. "La Vie". In: BOURGINE, Benoit et al. La Margelle du puits. Adolphe Gesché, une introduction. Paris: Cerf, 2013, p. 40.

${ }^{12}$ GESCHÉ, Adolphe. Les mots et lês livres. Paris: Cerf, 2004, p. 40.
} 
pois na Faculdade Católica de Louvain (1969-2003), ${ }^{13}$ passa a direcionar seu pensamento às questões teológicas de seu tempo. Experimentando toda efervescência da renovação teológica que precedeu, acompanhou e sucedeu-se ao Concílio, Gesché acompanha este espírito, mas num sentido todo particular. Se o Concílio acaba trazendo a necessidade de (re) pensar e (re) articular a Teologia a partir da intuição que fundamentou o Vaticano II (a Igreja passa a escutar o mundo), Gesché, movido dentro deste espírito percebe desde já, devido a certo retorno do sagrado, que o "mundo deseja escutar a fé". ${ }^{14}$ Não obstante, constata também a realidade crescente do ateísmo em seu tempo (ateísmo marxista; existencialista; científico; etc.), e pergunta-se se a negação de Deus em vista do humanismo não é devida também a certa ofuscação da Imagem de um Deus verdadeiro.

Diante desta realidade o projeto teológico de Gesché se direciona, portanto, na busca da compreensão de Deus e na afirmação de Deus como uma boa notícia aos homens, a partir da percepção de que talvez certa Imagem de Deus, mais influenciada pelo teísmo filosófico que culminou nos tratados escolásticos sobre Deus, tenha ofuscado a imagem do Deus bíblico, e que é necessário então recuperar a credibilidade desta imagem de Deus para os homens e mulheres deste tempo. Isso não somente para elaborar uma imagem de Deus mais adequada para a Teologia, mas porque para Gesché a questão do homem é também teológica ${ }^{15}$ e a questão de Deus é também antropológica (na busca de provar a existência de Deus o homem não buscava também uma autoafirmação, ou uma garantia de si?). Por isso, o homem sempre buscou conhecer-se a partir dos deuses: o conhece-te a ti mesmo sob o Oráculo de Delfos! ${ }^{16}$ Gesché busca falar de Deus porque pretende dizer algo ao ser humano.

Para Gesché, "Deus ou a ideia de Deus pode ajudar o homem a pensar,

\footnotetext{
${ }^{13}$ Gesché se tornou professor emérito em 1995, mas continuou atuando na Universidade até sua morte em 2003.

${ }^{14}$ Gesché fala em um tempo de "sinais que mostram um desejo de ouvir novamente a fé falar e dizer suas próprias palavras”. (GESCHÉ, Adolphe. O ser Humano. São Paulo: Paulinas, 2003, p. 6).

15 "Hannah Arendt conclui que a questão do ser humano não é menos teológica que a questão de Deus" (ibidem, p. 8).

16 "Desde sempre, para entender a si mesmo, o ser humano foi bater à porta dos deuses. Afinal de contas, não é no frontispio de um templo, em Delfos, que esta escrito o famoso 'Conhece-te a ti mesmo?"” (GESCHÉ, Adolphe. O ser Humano. São Paulo: Paulinas, 2003, p. 5).
} 
seja ele crente ou não", ${ }^{17}$ por que "para se pensar bem nada é demais". Para ele "a ideia de deus, mesmo como puro símbolo ou abstração, representa na historia do pensamento a ideia mais extrema, aquela além da qual ou aquém da qual não há nenhum conceito, falso ou verdadeiro, que seja mais definitivo". Assim, diante de Deus, ou da sua ideia, o homem pode lançar-se a pensar, e neste pensamento em excesso, pode lhe ver reveladas faces de sua própria existência, do mundo, da realidade, maneiras de aí estar, de aí habitar. Gesché, em sua obra derradeira, propõe "Deus para pensar", porque acredita haver em "Deus" a possibilidade de um discurso todo próprio "sobre" e "para" o homem.

Juntamente com a imagem de Deus, também para Gesché as "palavras da fé" (graça, salvação, redenção, pecado, etc.) tornaram-se para os homens contemporâneos "ininteligíveis". O trabalho do teólogo deve ser, portanto, recuperar o sentido e o poder de "revelação" destas "palavras de fé", e assim mostrar que o cristianismo possui um discurso inteligível, que não é irracional, e que é capaz de dar sentido existencial e direção ao homem na medida em que também o torna capaz de conhecer-se. Assim, na medida em que a Teologia possui uma antropologia (uma concepção de ser humano e um discurso para o ser humano), e uma antropologia que quer ser capaz de "revelar" ao ser humano um sentido, e assim revelar-lhe a ele mesmo (o conhece-te a ti mesmo diante dos deuses, diante de Deus), a Teologia possui algo que a aproxima da Literatura. Esta aproximação Gesché articulou em alguns artigos. Seguem alguns apontamentos sobre esta relação entre Literatura e Revelação em Teologia.

\section{Uma Teologia como Antropologia teologal - um espaço para a Literatura}

Gesché situa sua abordagem sobre Literatura na Teologia a partir da relação entre esta (Teologia) e a Antropologia. A questão que ele se coloca é: “A Teologia possui um lugar no conjunto dos discursos no qual o homem busca se compreender? Possui uma competência própria para dizer e dar a compreender alguma coisa sobre o homem?" Esta relação entre Teologia e antropologia vem articulada por duas questões: a-) "O que a antropologia tem a oferecer à reflexão teológica?” b-) “O que a Teologia tem à oferecer à antropologia, e as-

${ }^{17}$ GESCHÉ, Adolphe. $O$ mal. São Paulo: Paulinas, 2003, p. 5. 
sim ao homem que busca compreender-se?" Estas duas questões resumem-se em duas perspectivas para o teólogo: "Pode haver Teologia sem antropologia? Por sua vez, a antropologia não encontraria na Teologia interpelações pertinentes?" Para Gesché, a Teologia necessita da antropologia; principalmente a Teologia cristã, que afirma a realidade da encarnação. Por sua vez a antropologia pode encontrar intuições fecundas na Teologia, que lhe podem ajudar a refletir sobre o homem. ${ }^{18}$

Não se faz teologia com teologia, diz Gesché. Toda ciência se apoia em outras ciências. A Teologia não pode pretender se alimentar apenas de si mesma, sob o risco de degenerar-se. Por isso, a Teologia cristã sempre buscou recorrer às outras disciplinas do saber. Sem minimizar o valor de outras ciências no auxílio à Teologia, Gesché, no entanto, ressalta um lugar de destaque para a antropologia, pois, sendo a Teologia "ciência humana", ${ }^{19}$ que "falando" de Deus, fala de um Deus "para o ser humano", a antropologia passa a ser o lugar de verificação da verdade teológica, ${ }^{20}$ já que a verdade teológica não se verifica à maneira científica das ciências exatas, mas se verifica na medida em que é capaz de tornar a vida humana verdadeira. ${ }^{21}$ Para Gesché Deus não se "prova", mas "se prova", 22 ou "se experimenta" na vida e aí se verifica sua "racionalidade" ou seja, sua capacidade de tornar a vida verdadeira, cheia de sentido.

${ }^{18}$ Cf. GESCHÉ, Adolphe. "La théologie dans le temps de l'homme. Littérature et révélation". In: VERMEYLEN, J. (éd.). Cultures et théologies en Europe. Jalons pour un dialogue. Paris: Cerf, 1995, pp. 110-113.

${ }^{19}$ Não cabe discutir aqui o sentido da cientificidade da Teologia, que para Gesché possui uma racionalidade singular e um discurso todo próprio para o homem entre os discursos das diversas ciências, para isto cf. GESCHÉ, Adolphe. O ser humano. Paulinas: São Paulo, 2003, pp. 29-52. 20 "É essencialmente à antropologia que a teologia deve apelar para assegurar e verificar a competencia de seu discurso sobre o homem, e assim propor, entre outros, o seu discurso específico", por isso também que "sem base antropológica, a fé pode ser ininteligível ou mesmo ilusória”. GESCHÉ, Adolphe. "La théologie dans le temps de l'homme. Littérature et révélation”. In: VERMEYLEN, J. (éd.). Cultures et théologies en Europe. Jalons pour un dialogue. Paris: Cerf, 1995, p. 114.

21 “A antropologia, mais que as outras ciências humanas, é hoje decisiva para a Teologia pelo fato de que ela fala do homem, e isto constitui hoje o verdadeiro lugar cultural (eu não ignoro outros lugares de verificação da Teologia), o lugar por excelência e mais urgente de sua verdade. Eu diria: de sua verificação, de sua prova ou de sua provação. (...) Em teologia, em todo caso, não é mais suficiente, para verificar seu valor e sua relevância, a observação das afirmações da ciência histórica, da filologia ou da Filosofia. Pede-se uma ressonância mais profunda". (GESCHÉ, Adolphe. "La théologie dans le temps de l'homme. Littérature et révélation". In: VERMEYLEN, J. (éd.). Cultures et théologies en Europe. Jalons pour un dialogue. Paris: Cerf, 1995, p. 113).

${ }^{22}$ No Frances o trocadilho é mas visível: "non se prove, mais s'eprouve". 
Para Gesché, a Teologia parte de uma afirmação pura, sem prova, um anúncio (Kerigma). Porém, este anúncio não é arbitrário e destituído de um sentido de verificação. Diz Gesché: "Nós lidamos, em Teologia, com proposições que poderiam se chamar "veritantes", por que elas fornecem e mostram (ou não) sua verificação nos frutos que lhes dão seu exercício existencial", e justifica: "Isto não é também um processo de verificação?: o homem que faz hipótese da fé é este que se pergunta e verifica (ou não) se ele tornou-se mais verdadeiro, mais verídico, mais verificado de se compreender como imagem de Deus e compreender os outros da mesma maneira". ${ }^{23}$

A Teologia propõe um discurso "a partir do alto", do infinito. O homem é irredutível ao reino do finito (Descartes), é um ser "não calculável", inexato. Por isso não se satisfaz com um discurso meramente analítico ou explicativo sobre si mesmo (Os discursos da ciência, que possuem seu valor). O homem é perpassado por um enigma, por "realidades" que não se deixam enquadrar nos ditames da ciência. Por isso tem necessidade de um discurso "excessivo", que lhe aponte caminhos, lhe sinalize uma direção (precisa para isso de linguagens de sinal, de símbolo de mitos, etc.), precisa de "palabras en excesso que apuntam absolutos". ${ }^{24} \mathrm{~A}$ antropologia proporcionada pela Teologia (antropologia teologal) é uma antropologia de revelação porque oferece uma palavra de sentido, no qual o homem pode descobrir-se a si mesmo diante do infinito, sendo também uma antropologia de destinação por que aponta um futuro absoluto - Reino de Deus, Terra Prometida, Salvação - que, no entanto, perfaz a história do homem neste mundo, conferindo-lhe direção, situando-o em face ao infinito, que percebe que anseia. A Filosofia contemporânea redescobriu (a partir da antropologia cultural) o valor dos mitos, da linguagem simbólica, da poesia, ${ }^{25}$ etc.. Percebeu que o ser humano não busca conhecer-se somente analiticamente (sua biologia; sua psicologia - não tão exata assim...-; sua química;

${ }^{23}$ GESCHÉ, Adolphe. "La théologie dans le temps de l'homme. Littérature et révélation". In: VERMEYLEN, J. (éd.), Cultures et théologies en Europe. Jalons pour un dialogue. Paris: Cerf, 1995, p. 116.

${ }^{24}$ RODRIGUES, Paulo. Pensar al hombre. Antropologia teológica de Adolphe Gesché. Salamanca: Publicaciones Universidad Pontificia Salamanca, 2012, p. 44.

25 "Porque el hombre se mueve en un mundo desconocido, y no en un mundo de evidencias, necesita de una iniciación, de recibir signos, claves y anticipaciones para comprender la realidad. Los mitos, cuentos, leyendas, historias y relatos constituyen las respuesta-preguntas, herencia de palabras y simbolos que enseñan e introducen al hombre en un imaginario literario que le permite acercarse a la comprensión de la realidad." (RODRIGUES, Paulo. Pensar al hombre. Antropologia teológica de Adolphe Gesché. Salamanca: Publicaciones Universidad Pontificia Salamanca, 2012, pp. 50-51). 
sua história), mas que também busca conhecer-se a partir do "sentido", do "infinito", do "futuro", etc.. Por isso, de fato, a Teologia possui seu lugar, pois:

Se a Teologia traz algo ao ser humano, é essencialmente na medida em que, para compreender-se, o ser humano tem necessidade de se medir com o que, realidade ou ideia, vem-lhe de um de fora, e cujo rumor temos o direito e o dever de fazer escutar. A teologia, falando de Deus, (...), propõe uma compreensão pelo alto e pelo infinito, e essa maneira de fazer pode apresentar-se como hermenêutica (revelação) do ser humano pelo infinito. ${ }^{26}$

Compartilhando do pensamento de Franz Rosenzweig, Gesché concorda que as palavras "criação, redenção e revelação" possuem não somente significado religioso, mas também um significado antropológico geral:

O ser humano é um ser que se descobre como criado: não me fiz a mim mesmo, sou precedido, não poderia compreender-me pensando-me como minha própria origem (...). O ser humano é um ser que se indaga sobre seu destino, sobre uma salvação, sobre uma redenção: salvarei a minha vida do não-sentido? O ser humano, enfim, é um ser que procura uma revelação do que ele é, ocupado no labirinto de seu enigma, desse 'algo essencialmente surdo' que descobre nele (Davidson), mas do qual espera a revelação ${ }^{27}$

A Teologia pode se constituir num discurso todo próprio ao ser humano, porque justamente procura falar de criação, redenção (salvação) e revelação, ${ }^{28}$ "introduzindo inverificáveis e incógnitas, como faz o matemático para responder a questões que de outra maneira não consegue ter ideia de como resolver", ${ }^{29}$ trazendo "uma palavra que, seja lá como se chegue a ela, poderia ajudar (o homem) a compreender a si mesmo". ${ }^{30}$ Para compreender este lugar e esta função da Teologia, Gesché aproxima a linguagem teológica à linguagem literária, e aí situa sua noção de Revelação.

\footnotetext{
${ }^{26}$ GESCHÉ, Adolphe. O sentido. São Paulo: Paulinas, 2003, p. 156.

${ }^{27}$ GESCHÉ, Adolphe. O sentido. São Paulo: Paulinas, 2003, p. 158.

28 “A Teologia 'fala' do homem como 'revelado' em sua ultima grandeza diante de Deus, por sua doutrina da Criação, da Encarnação e da Salvação". (GESCHÉ, Adolphe. "L'anthropologie théologale chrétienne, une anthropologie de révélation”. In: GESCHÉ A.; AGHA, Kadri. “Conférences du Centre El Kalima 20”. Bruxelles: Centre El Kalima, 1993, p. 7).

${ }^{29}$ GESCHÉ, Adolphe. O sentido. São Paulo: Paulinas, 2003, p. 157.

${ }^{30}$ GESCHÉ, Adolphe. O ser humano. São Paulo: Paulinas, 2003, p. 6.
} 


\section{Do imaginário literário ao teológico: fontes de revelação}

Da experiência que fez com as palavras e os livros, Gesché compreendeu a força e a fonte de conhecimento que aí existiam. Gesché de certa forma elabora toda uma "metafísica das palavras", pois percebe que o ser humano constitui "seu mundo" através das palavras, já que "sem as palavras, a realidade é opaca". ${ }^{31}$ Se Deus criou o mundo, por sua vez o homem é que lhes dá existência fazendo-as existir em "seu mundo". Por isso, para Gesché, Deus deu ao homem a capacidade de "nomear" as coisas, ou seja, de fazê-las existir de maneira toda própria em "seu mundo". As palavras possuem então poder de revelação, já que "as palavras significam, mais que designam (as palavras - signi-fient; font signe) e isso vai mais longe do que simplesmente denominar. As palavras não demonstram, elas mostram além delas mesmas, no sentido forte que a fenomenologia dá à palavra "mostração"." ${ }^{32}$ Para Gesché a palavra possui esta força "criadora" e "reveladora" de mundo, isso porque "palavra" (verbo, Logos), não deixa de ter analogia com a Palavra Divina (que cria e revela).

Este mesmo poder de "revelação" das palavras, possuem os livros, a literatura. "A literatura age, não é simples espetáculo ou divertimento. Tem poder de revelação". ${ }^{33}$ Diante da parcela de enigma que há em si (no homem), nas pessoas, no mundo (e também em Deus), o homem não esgota tais realidades somente pela razão; por isso, para compreender-se, precisa chegar à esfera do imaginário. ${ }^{34}$ Aí a literatura, as histórias e "estórias" têm seu lugar, inclusive antropológico (antropologia literária), no sentido de dar a conhecer aspectos do ser humano que escapam aos métodos científicos. Para Gesché, "a literatura pode ser considerada como verdadeiro lócus, como verdadeiro lugar epistemológico do ser humano", pois ela "libera o campo de abordagem do ser

\footnotetext{
${ }^{31}$ GESCHÉ, Adolphe. Les mots et lês livres. Paris: Cerf, 2004, p. 11.

${ }^{32}$ Ibidem, p. 12.

${ }^{33}$ GESCHÉ, Adolphe. O sentido. São Paulo: Paulinas, 2003, p. 147.

${ }^{34}$ Para descobrir ou construir o sentido, o ser humano não pode confiar unicamente na racionalidade. Ele precisa de outra esfera, mais vasta, a do imaginário. O imaginário é um desses lugares no qual ele procura compreender-se e dar sentido a sua existência. O imaginário é aquele de toda uma tradição onde ele se enraíza, feita de mitos, de contos e de lendas. (...) é a vida que se agita em nós, com nossa sensibilidade, nossa afetividade e nossas emoções. Todo esse imaginário (...), "todas essas histórias que nós nos contamos" vai infinitamente mais longe como poder que agrega, que nossa razão (ibidem, p. 139). Há no "imaginário antropológico uma verdadeira capacidade de revelação" (ibidem, p. 155).
} 
humano graças a um desenrolar do imaginário, em que tudo é possível e em que nada é impossível, em que nada é deixado de lado do que poderia fazer ou do que poderia ser um ser humano". ${ }^{35}$ Para o autor, "a ficção ensina-nos, enormemente, sobre o ser humano, e as vezes bem mais e bem melhor do que a antropologia racional". ${ }^{36}$

A Literatura constitui-se então em lugar de conhecimento do ser humano. Gesché constata esta capacidade que a Literatura possui de descortinar aspectos da realidade: "Pela ficção, pelos processos de invenção imaginativa, descobre-se, no sentido forte do termo, o que o ser humano é ou pode ser", ${ }^{37}$ em outras palavras, Gesché percebe aí uma capacidade de revelação do ser humano. Diz ele: "quantas palavras podem nos abrir à realidade! Não foi num romance de Flaubert que Sartre descobriu melhor o ser humano do séc. XIX?" e, citando outros exemplos, conclui: "a relação não é distante entre o que uns chamam revelação, e outros ficção". ${ }^{38}$ E como Gesché entende "Revelação"? Diz ele: "Compreendo aqui 'Revelação' não no sentido em que se tenha recebido alguma coisa caída do céu, mas no sentido que se diz: 'isto verdadeiramente me revelou a mim mesmo', me fez descobrir". ${ }^{39}$ A partir disso Gesché percebe analogias entre Literatura e Teologia, a começar pela forma com que na Literatura o autor é perpassado por uma inspiração reveladora.

A Literatura é coleta e invenção intimamente mescladas, mas, ao mesmo tempo, essa invenção, e por isso mesmo que é também coleta de nossas mais primitivas emoções, não é puro delírio, porque o verdadeiro romancista, que escuta sua imaginação, sabe muito bem que algo se impõe a ele. Ele inventa, mas não inventa uma coisa qualquer. É por isso - e entrevemos agora o elo que pode haver entre literatura e teologia - que o romance não é uma aventura ao acaso para o teólogo (...) Há na descoberta romanesca uma analogia com o que o teólogo chama de revelação: uma visitação. $\mathrm{O}$ encontro de algo inesperado, súbito, 'revelado', fora do real cotidiano e, entretanto, inscrito nele." ${ }^{40}$

\footnotetext{
35 ibidem, p. 142.

36 ibidem, p. 149.

${ }^{37}$ ibidem, p. 149.

${ }^{38}$ GESCHÉ, Adolphe. O sentido. São Paulo: Paulinas, p. 150.

${ }^{39}$ GESCHÉ, Adolphe. "L'anthropologie théologale chrétienne, une anthropologie de révélation”. In: GESCHÉ, A.; AGHA, Kadri. Conférences du Centre El Kalima 20. Bruxelles: Centre El Kalima, 1993, p. 16.

${ }^{40}$ GESCHÉ, Adolphe. O sentido. São Paulo: Paulinas, p. 150.
} 
Ele percebe na inspiração artística (aqui no caso do romancista) uma analogia com a inspiração por meio da qual se estabelece a 'Revelação' judaico cristã. Gesché admira o "milagre da criação literária, um poder propriamente divino, o poder do Logos". ${ }^{41}$ A Escritura Sagrada também não deixa de ser 'Literatura' permeada de símbolos, de metáforas, de mitos e figuras, representações que fecundam um imaginário todo singular. De fato, "Como fala a fé? Utilizando todo um universo de representações (Kant) que servem de base e sustentam seu sentido. Que seria o cristianismo sem o formidável fundo de imaginário que desde a origem ele veicula e continua a veicular?". ${ }^{42}$

Nesse universo de representações (reino de Deus, graça, salvação, perdão, Terra Prometida, História da Salvação) o ser humano pode se adentrar, situar-se, encontrar sentido e uma forma de ampliar horizontes para "ler" a realidade a partir da fé. O discurso teológico, fundado neste universo de representações da Revelação bíblica, não é destituído de racionalidade, de sentido. Por isso diante das "proposições da fé" mergulhadas neste imaginário fecundado pelas Escrituras, "O homem que faz a hipótese de fé é este que se perguntará e verificará (ou não) se ele tornou-se mais verdadeiro, mais verídico, mais cerificado ao se compreender como imagem de Deus e de compreender os outros da mesma maneira". ${ }^{43}$ Há, portanto, uma analogia entre revelação e literatura também na perspectiva do leitor, que no contato com uma obra literária pode ver descortinado diante de si "novos horizontes" da realidade, e verdadeira revelação de novas perspectivas de vida. "Quando há revelação, se não no momento em que um texto surge subitamente dele mesmo e me visita sem preâmbulo?"44

\section{Conclusão}

Seja na perspectiva do romancista (sua inspiração reveladora), como também na do leitor, existe uma experiência de "revelação" na Literatura que pode iluminar um sentido de "revelação" mais dinâmico e existencial para o teólogo.

${ }^{41}$ LOBET, Benoit. "La Litterature". In: BOURGINE, Benoit et al. La Margelle du puits. Adolphe Gesché, une introduction. Paris: Cerf, 2013, p. 249.

${ }^{42}$ GESCHÉ, Adolphe. O sentido. São Paulo: Paulinas, p. 152.

${ }^{43}$ GESCHÉ, Adolphe. "La théologie dans le temps de l'homme. Littérature et révélation". In: VERMEYLEN, J. (éd.). Cultures et théologies en Europe. Jalons pour un dialogue. Paris: Cerf, 1995, p. 116.

${ }^{44}$ GESCHÉ, Adolphe. O sentido. São Paulo: Paulinas, pg. 151 
Na teologia contemporânea, a questão de Deus revisita a questão da revelação tal qual o pensamento poético é visto como modo de desvelamento de sentido (...) A revelação passa a ser entendida como desvelamento de um Mistério de excesso de sentido que perpassa a existência (...) A questão da revelação passa a ser lida, portanto, a partir da experiência da busca de sentido (...) Deste modo a revelação deixa de ser lida como um conjunto de verdades, para ser vista como a experiência fundacional de um modo de descobrir uma experiência de sentido. ${ }^{45}$

Gesché buscou construir sua teologia nesta perspectiva. Para ele "Um critério de justeza e da verdade de uma proposição teológica é que ela seja revelante. Quando pois, um texto, seja qual for, é "revelado"? Quando é e por que é revelante, quando e por que me revela e me descobre a mim mesmo". ${ }^{46}$ Neste sentido, o discurso teológico, mais do que ter em vista uma "verdade doutrinal", abstrata e teórica, deve buscar ser reveladora (estar a serviço da Revelação) sendo revelante e relevante, estando conectada com a vida humana!

A teologia deve constituir-se neste lugar no qual o ser humano pode "ler-se", "conhecer-se", conhecer a realidade, o mundo, as pessoas, tal qual na literatura em que ele pode se ver revelado diante de mundos nunca antes imagináveis, e que lhe descortina inúmeras possibilidades e horizontes de perspectivas no qual aprofunda o conhecimento de si mesmo. Se há uma analogia, há também uma especificidade do discurso teológico frente à linguagem literária, não em contradição, mas no sentido de um "ir mais além" do abrir horizontes das possibilidades puramente literárias. É que pela fé (confiança na vida, no sentido, a partir de Deus), "o crente crê poder colocar o infinito em sua vida", pondo o sentido de sua vida em "relação com um desígnio divino: a chegada do Reino de Deus". ${ }^{47}$ Quanta possibilidade de o homem aí descobrir-se a si mesmo (e descobrir o outro)! Sua grandeza e também contingência (pecado), e de assim lançar-se na aventura humana na perspectiva de um infinito que se revela como Amor! A Teologia deve "oferecer ao ser humano um discurso específico e que somente ela pode

\footnotetext{
${ }^{45}$ VILLAS BOAS, Alex. "A questão de Deus entre a teologia e a literatura contemporânea". Forma Breve 11 (2014), pp. 83-84.

${ }^{46}$ GESCHÉ, Adolphe. O sentido. São Paulo: Paulinas, 2003, p. 151.

${ }^{47}$ GESCHÉ. Adolphe. La paradoja de la fe. Salamanca: Síguime, 2013, p. 48.
} 
oferecer"; 48 discurso do alto, a partir do infinito capaz de "revelação", discurso do qual Gesché exclama com uma interrogação àqueles que possam lançar-se numa desconfiança: "E será que é proibido ler o ser humano in excelsis?". ${ }^{49}$

\section{Referências bibliográficas}

BOTTIGHEIMER, Christoph. Manual de Teologia Fundamental: A racionalidade da questão de Deus e da Revelação. Petrópolis: Vozes, 2014, p. 44.

BOURGINE, Benoit et al. La Margelle du puits. Adolphe Gesché, une introduction. Paris: Cerf, 2013.

CONCILIO VATICANO II. "Constituição Dogmática Dei Verbum”. In: Documentos do Concílio Ecumênico Vaticano II. São Paulo: Paulus, 2001, pp. 247-367.

GESCHÉ, Adolphe. "L'anthropologie théologale chrétienne, une anthropologie de révélation”. In: AGHA, Kadri. Conférences du Centre El Kalima 20. Bruxelles: Centre El Kalima, 1993, pp. 3-20.

GESCHÉ. Adolphe. La paradoja de la fe. Salamanca: Síguime, 2013.

GESCHÉ, Adolphe. "La théologie dans le temps de l'homme. Littérature et révélation". In: VERMEYLEN, J. (éd.). Cultures et théologies en Europe. Jalons pour un dialogue. Paris: Cerf, 1995, pp. 109-142.

GESCHÉ, Adolphe. Les mots et lês livres. Paris: Cerf, 2004.

GESCHÉ, Adolphe. O mal. São Paulo: Paulinas, 2003.

GESCHÉ, Adolphe. O sentido. São Paulo: Paulinas, 2003.

GESCHÉ, Adolphe. O ser Humano. São Paulo: Paulinas, 2003.

MANZATTO, Antonio. Teologia e Literatura: reflexão teológica a partir da antropologia contida nos romances de Jorge Amado. São Paulo: Edições Loyola, 1994.

RODRIGUES, Paulo. Pensar al hombre. Antropologia teológica de Adolphe Gesché. Salamanca: Publicaciones Universidad Pontificia Salamanca, 2012.

\footnotetext{
${ }^{48}$ GESCHÉ, Adolphe. O ser humano. São Paulo: paulinas, 2003, p. 51.

${ }^{49}$ Ibidem, p. 52.
} 
ROUSSEAU, Hervé. “A Literatura: Qual é seu poder teológico?”. Concilium 115 (1976/5), pp. 7-15.

VILLAS BOAS, Alex. "A questão de Deus entre a teologia e a literatura contemporânea”. Forma Breve 11 (2014), pp. 83-97.

Alexandre Patucci de Lima Mestre em Teologia pela Pontifícia Universidade Católica de São Paulo São Paulo / SP - Brasil E-mail: aleofmconv@hotmail.com

Recebido em: 21/05/15 Aprovado em: 16/07/15 